\title{
Novel polymorphic microsatellite markers from turmeric, Curcuma longa L. (Zingiberaceae)
}

\author{
Siju Senan ${ }^{1}$, Dhanya KizhakayiL ${ }^{1}$, ThotTen E. Sheeja ${ }^{1 *}$, \\ Bhaskaran Sasikumar $^{1}$, Alangar I. Bhat ${ }^{2}$, VILluPanoor A. Parthasarathy ${ }^{1}$ \\ ${ }^{1}$ Division of Crop Improvement and Biotechnology, Indian Institute of Spices Research, \\ Calicut, Kerala 673 012, India \\ 2 Division of Crop Protection, Indian Institute of Spices Research, Calicut, Kerala 673 \\ 012, India
}

\begin{abstract}
Twenty one polymorphic microsatellite loci were isolated and characterized from turmeric (Curcuma longa L.). These markers were screened across thirty accessions. The number of alleles observed for each locus ranged from two to eight with an average of 4.7 alleles per locus. The discrimination power of these markers ranged from 0.25 to 0.67 (average 0.6). The simple sequence repeat (SSR) markers can complement the currently available SSR markers and would be useful for the genetic analysis of turmeric accessions.
\end{abstract}

Keywords: Curcuma longa, Microsatellites, triploid, turmeric.

Abbreviations: SSR - simple sequence repeat, PCR - polymerase chain reaction, EST - expressed sequence tags.

\section{Introduction}

Turmeric (Curcuma longa L.) is an important spice and medicinal plant cultivated widely in South-East Asian countries, with India as its prime producer. Curcumin, the main bioactive component of turmeric has been shown to exhibit a wide range of biological actions (ChATTOPADHYAY et al. 2004) and its medicinal properties are well documented (AgGARWAL et al. 2007). Turmeric is mainly propagated through rhizomes and is reported to be a triploid [ $2 \mathrm{n}=3 \mathrm{x}=63 ; \mathrm{x}=21$ ] (RAMACHANDRAN 1961, ISLAM 2004) and a nonaploid $(2 \mathrm{n}=9 \mathrm{x}=63 ; \mathrm{x}=7)$ (SKORNICKOVA et al. 2007). Conservation and utilization strategies require fundamental knowledge of the extent of genetic diversity of the crop. Conventionally, turmeric accessions are characterized using morphological and agronomical traits. Microsatellite or Simple Sequence Repeat (SSR) constitutes a robust set of molecular markers

* Corresponding author, e-mail: teshee@rediffmail.com Copyright ${ }^{\circledR} 2013$ by Acta Botanica Croatica, the Faculty of Science, University of Zagreb. All rights reserved. 
widely used for population genetic analyses, germplasm characterization, parentage analysis and marker-assisted selection in plants. So far only 17 EST-SSR (SIJU et al. 2010a) and 35 genomic SSR markers (SIGRIST et al. 2010, SiJu et al. 2010b) have been reported in turmeric. This limited availability warrants the need to expand the existing repertoire of microsatellite markers for future studies aiming at better estimation of genetic variability for the effective conservation of the genetic resources of turmeric. The present study was conducted to develop novel microsatellite markers from genomic DNA libraries of turmeric.

\section{Materials and methods}

Total genomic DNA was extracted from a wild turmeric accession maintained at the germplasm repository of the Indian Institute of Spices Research, Calicut, India using the modified CTAB protocol (SYAMKUMAR et al. 2003). Genomic libraries enriched for microsatellite repeats were constructed following the protocol of GLENN and SCHABLE (2005) with four sets of 3' biotinylated probes- $(\mathrm{TG})_{12},(\mathrm{AAC})_{6},(\mathrm{AAG})_{8}$ and $(\mathrm{ACAG})_{6}$. Plasmids were isolated from 268 recombinant clones and sequenced at Bioserve Biotechnologies, Hyderabad, India. The sequences were assembled into contigs using EGassembler (MASOUDI-NEJAD et al. 2006) and the identification of SSRs within the sequenced clones was performed using WebSat (MARTINS et al. 2009). Primers targeting the amplification of unique microsatellite repeats were designed using the web-based computer program- Primer3 (ROZEN and SKALETSKY 2000).

Polymorphism was assessed by genotyping thirty turmeric accessions maintained in the repository. Each $25 \mu \mathrm{L}$ of PCR mixture contained 1 X Taq buffer (Sigma, Missouri, USA), $1.5 \mathrm{mM} \mathrm{MgCl}_{2}, 0.2 \mathrm{mM}$ of dNTPs, 5.0 pmol each of primers, $50 \mathrm{ng}$ genomic DNA and $1 \mathrm{U}$ Taq DNA polymerase (Sigma, Missouri, USA). PCR amplification was performed on a Master Cycler EP Gradient S thermocycler (Eppendorf, Germany) with the following profile: 1 cycle of $94^{\circ} \mathrm{C}$ for $5 \mathrm{~min}$; followed by 35 cycles of $94^{\circ} \mathrm{C}$ for $30 \mathrm{~s}$, annealing at optimal temperature (Tab. 1) for $45 \mathrm{~s}, 72^{\circ} \mathrm{C}$ for $1 \mathrm{~min}$; and 1 cycle of $72{ }^{\circ} \mathrm{C}$ for $20 \mathrm{~min}$. PCR products were sized on $8.0 \%$ denaturing PAGE along with a 10-bp DNA ladder (Invitrogen, Carlsbad, CA) and silver stained (BENBOUZA et al. 2006). The efficiency of microsatellite loci in genotype identification was evaluated with a discriminating power parameter (D), which represents the probability that two randomly chosen individuals have different patterns, and thus are distinguishable (TESSIER et al. 1999).

\section{Results and discussion}

Sequencing of these 268 clones revealed a total of 123 sequences containing microsatellites. After redundancy elimination, only 92 sequences contained unique SSRs having repeat units ranging from 4 to 21 . Thus the efficiency of microsatellite isolation using the enrichment protocol accounted for 34\% (92 unique sequences out of 268 sequenced clones). High proportions of DNA fragments lacking microsatellite repeats is a significant issue with the improved protocols of microsatellite isolation protocols, due to the high level of non-specific binding of streptavidin-coated magnetic beads to the target DNA (ST. JOHN and QUINN 2008). However the redundancy (25\%) observed in the present study might be due to the application of PCR steps during enrichment, which might have amplified the same genomic DNA fragments prior to cloning. Though efficient enrichment protocols 


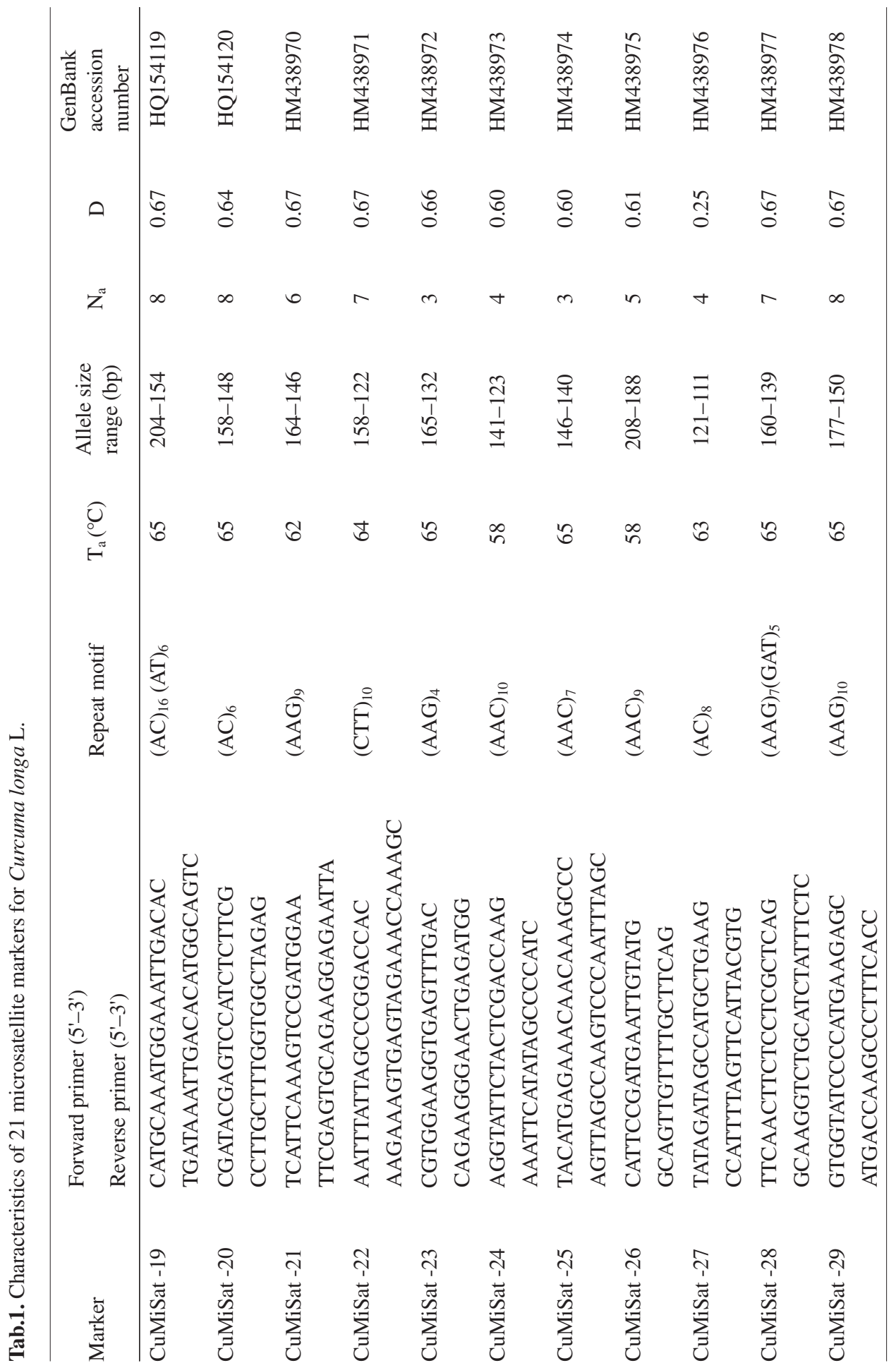




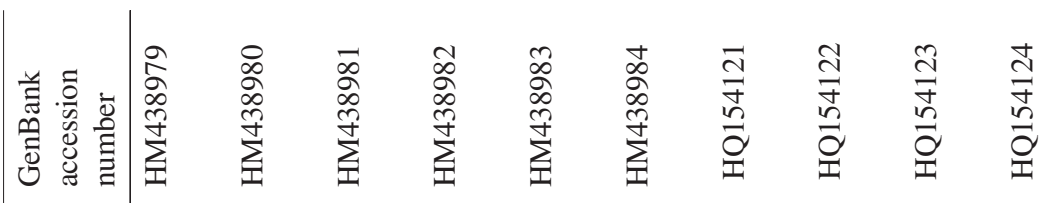

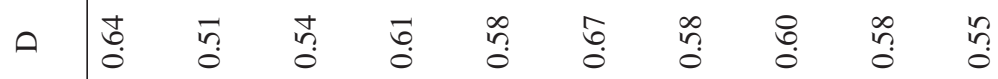

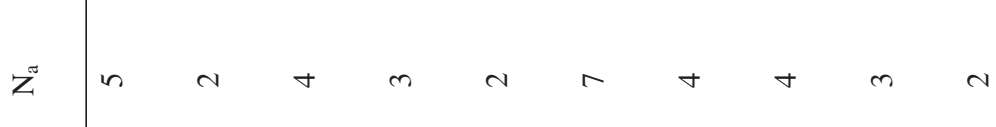

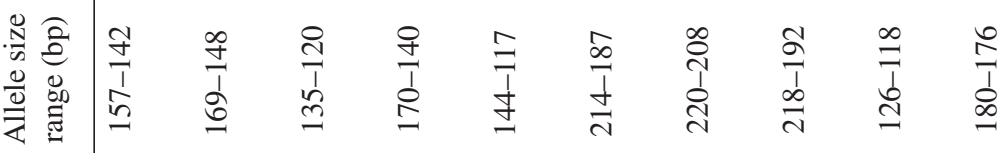

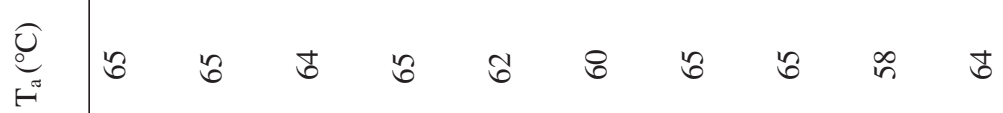

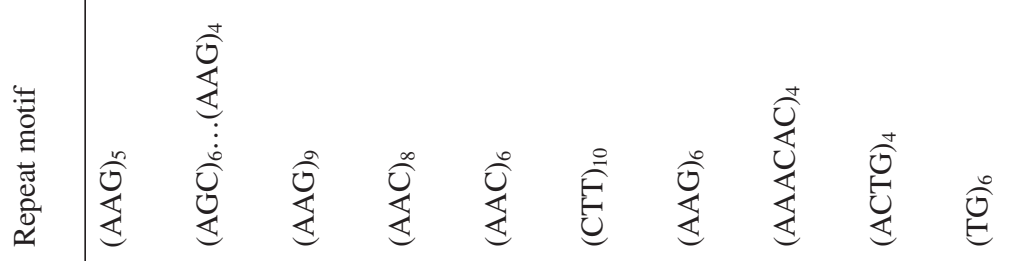

$$
\text { (1) }
$$

|

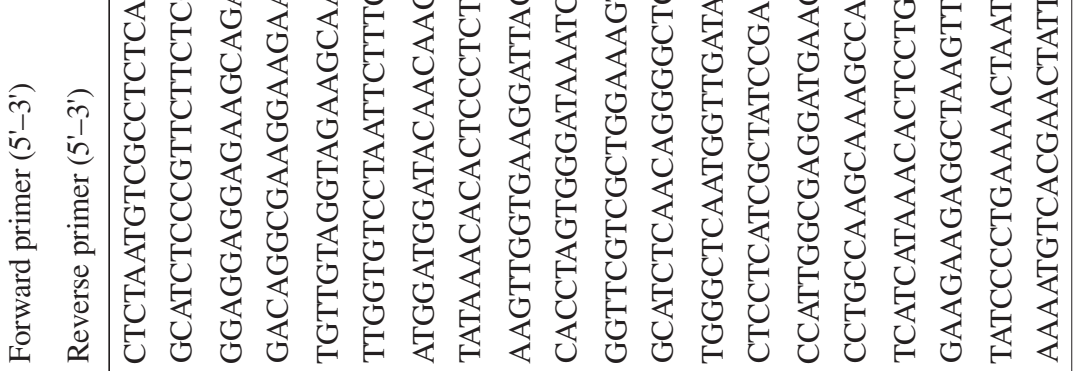

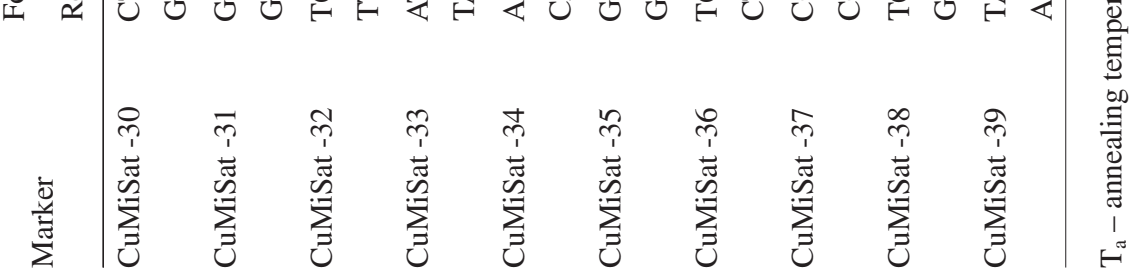


might give higher number of positive clones this could also lead to higher levels of redundancy (SQuiRRELl et al. 2003). Out of the eighty primers designed and targeted for the amplification, twenty one polymorphic markers were identified (Tab 1). These markers generated a maximum of three alleles per genotype, tallying with the triploid status of turmeric (RAMACHANDRAN 1961, ISLAM 2004) and characteristics of SSRs reported earlier (SIGRIST et al. 2010; SIJU et al. 2010a, b). A total of 99 alleles were detected across 30 turmeric accessions with an average of 4.7 alleles/ locus. The number of alleles per locus varied from 2 (CuMiSat 31, 34, 39) to 8 (CuMiSat 19, 20, 29). To evaluate the efficiency of SSR markers for discriminating turmeric accessions/varieties, the discrimination power (D) of markers was calculated according to TESSIER et al. (1999). The D value for these markers ranged from 0.25 (CuMiSat 27) to 0.67 (CuMiSat 19, 21, 22, 28, 29, 35) with an average value of 0.6. This is almost on a par with the previous report of turmeric microsatellites (SIJU et al. 2010b), suggesting their potential utility in future studies aimed at genetic diversity analysis and marker-assisted selection in the species.

\section{Acknowledgements}

This research was supported by a research grant from the Department of Biotechnology (DBT), New Delhi, India.

\section{References}

Aggarwal, B. B., Bhatt, I. D., Ichikawa, H., Ahn, K. S., Sethi, G., Sandur, S. K., Sundaram, C., Seeram, N., Shishodia, S., 2007: Curcumin - biological and medicinal properties. In: RaVindRAN, P. N., BABU, K. N., Sivaraman, K. (eds.), Turmeric: the genus Curcuma, 297-368. CRC Press, New York.

Benbouza, H., Jacquemin, J. M., Baudoin, J. P., Mergeai, G., 2006: Optimization of a reliable, fast, cheap and sensitive silver staining method to detect SSR markers in polyacrylamide gels. Biotechnology Agronomy Society and Environment 10, 77-81.

Chattopadhyay, I., Biswas, K., BAndyopadhyay, U., BanerJeE, R. K., 2004: Turmeric and curcumin: biological actions and medicinal applications. Current Science 87, 44-53.

Glenn, T. C., Schable, N. A., 2005: Isolating microsatellite DNA loci. Methods in Enzymology 395, 202-222.

IsLAM, M. A., 2004: Genetic diversity of the genus Curcuma in Bangladesh and further biotechnological approaches for in vitro regeneration and long-term conservation of $C$. longa germplasm. PhD Thesis, University of Hannover.

Martins, W. S., Lucas, D. C. S., Neves, K. F. S., Bertioli, D. J., 2009: WebSat - Web software for microsatellite marker development. Bioinformation 3, 282-283.

Masoudi-Nejad, A., Tonomura, K., Kawashima, S., Moriya, Y., Suzuki, M., Itoh. M., KANEHISA, M., ENDO, T., Goto, S., 2006: EGassembler: online bioinformatics service for large-scale processing, clustering and assembling ESTs and genomic DNA fragments. Nucleic Acids Research 34, W459-462.

RAMACHANDRAN, K., 1961: Chromosome numbers in the genus Curcuma Linn. Current Science 30, 194-196. 
Rozen, S., Skaletsky, H. J., 2000: Primer 3 on the WWW for general users and for biologist programmers. In: Krawetz, S., Misener, S. (eds.), Bioinformatics methods and protocols: methods in molecular biology, 365-386. Humana Press, Totowa, NJ.

Sigrist, M. S., Pinheiro, J. B., Azevedo-Filho, J. A., Colombo, C. A., Bajay, M. M., Lima, P. F., Camilo, F. R., Sandhu, S., Souza, A. P., Zucchi, M. I., 2010: Development and characterization of microsatellite markers for turmeric (Curcuma longa). Plant Breeding 129, 570-573.

Siju, S., Dhanya, K., Syamkumar, S., Sasikumar, B., Sheeja, T. E., Bhat, A. I., ParthaSARATHY, V. A., 2010a: Development, characterization and cross species amplification of polymorphic microsatellite markers from expressed sequence tags of turmeric (Curcuma longa L.). Molecular Biotechnology 44, 140-147.

Siju, S., Dhanya, K., Syamkumar, S., Sheeja, T. E., Sasikumar, B., Bhat, A. I., ParthaSARATHY, V. A., 2010b: Development, characterization and utilization of genomic microsatellite markers in turmeric (Curcuma longa L.). Biochemical Systematics and Ecology 38, 641-646.

Skornickova, J. L., Sida, O., Jarolimova, V., Sabu, M., Fer, T., TravniceK, P., Suda, J., 2007: Chromosome numbers and genome size variation in Indian species of Curcuma (Zingiberaceae). Annals of Botany 100, 505-526.

Squirrell, J., Hollingsworth, P. M., Woodhead, M., Russell, J., Lowe, A. J., GibBy, M., POWELL, W., 2003: How much effort is required to isolate nuclear microsatellites from plants? Molecular Ecology 12, 1339-1348.

ST. John, J., QuinN, T. W., 2008: Rapid capture of DNA targets. Biotechniques 44, 259-264.

SyAmkUMAR, S., LOWARENCE, B., SASIKUMAR, B., 2003: Isolation and amplification of DNA from rhizomes of turmeric and ginger. Plant Molecular Biology Reporter 21, 171a$171 \mathrm{e}$.

Tessier, C., David, J., This, P., Boursiquot, J. M., Charrier, A., 1999: Optimization of the choice of molecular markers for varietal identification in Vitis vinifera $\mathrm{L}$. Theoretical and Applied Genetics 98, 171-177. 